\title{
$\begin{array}{ll}\text { Research Square } & \begin{array}{l}\text { Preprints are preliminary reports that have not undergone peer review. } \\ \text { They should not be considered conclusive, used to inform clinical practice, } \\ \text { or referenced by the media as validated information. }\end{array}\end{array}$
}

\section{Risk factors for acute kidney injury after Stanford type A aortic dissection repair: a systemetic review and meta-analysis}

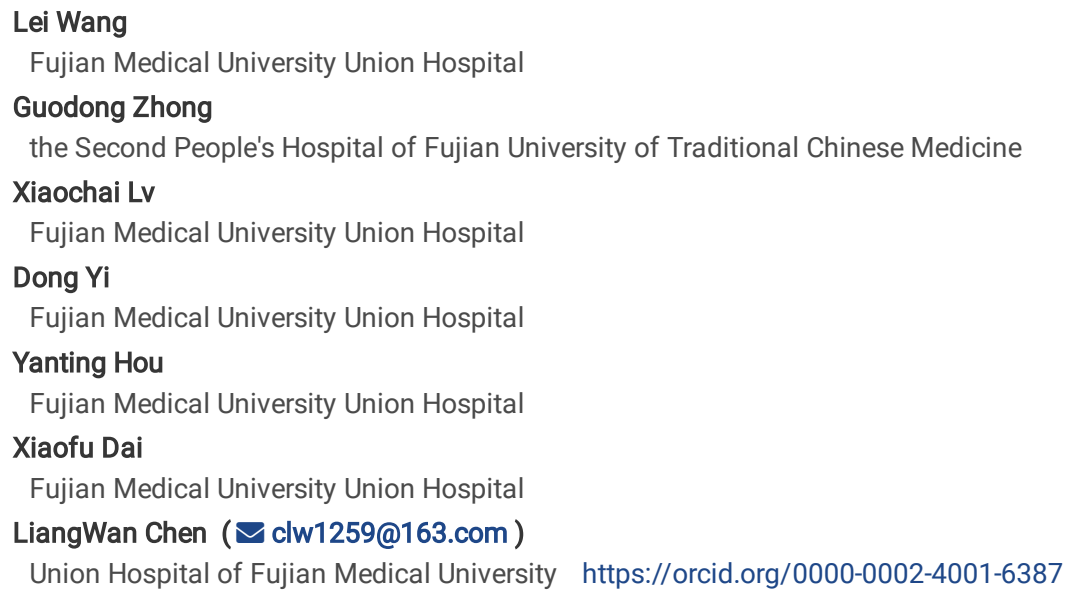




\section{Abstract}

Background Acute kidney injury (AKI) is one of the most common complications after Stanford type A aortic dissection (TAAD) repair surgery, but its risk factors are inconsistent in different studies. So this meta-analysis was conducted to systematically analyze the risk factors for AKI after TAAD repair surgery, so as to early identify the therapeutic targets for preventing AKI and to improve the outcomes.

Methods Studies on risk factors for AKI after TAAD repair surgery were searched from PubMed, Embase, Cochrane library and Web of science from inception of databases to June 2021. The meta-analysis was performed by Stata 16.0 software. The combined incidence and risk factors of AKI and its impact on mortality after TAAD repair surgery were calculated.

Results A total of 11 studies and 4156 patients were included. The combined incidence of postoperative AKI was $56.0 \%$. The advanced age [odds ratio $(\mathrm{OR})=1.32,95 \%$ confidence interval $(\mathrm{Cl})(1.19,1.47), P<0.001]$, cardiopulmonary bypass time $>180$ minutes $[\mathrm{OR}=4.88,95 \% \mathrm{Cl}(2.05,11.59), P<0.001]$, red blood cell (RBC) volume transfused perioperatively [OR=1.13, 95\% $\mathrm{Cl}(1.03,1.24), P<0.01]$, high body mass index [OR=1.22, 95\% $\mathrm{Cl}(1.18,1.27), P<0.001]$ and preoperative renal malperfusion [OR $=5.32,95 \% \mathrm{Cl}(2.92,9.71), P<0.001]$ were risk factors for AKI after TAAD repair surgery. The in-hospital mortality [rate ratio $(\mathrm{RR})=2.50,95 \% \mathrm{Cl}(1.82,3.44), P<0.001]$ and 30-day mortality [RR=2.81, 95\% $\mathrm{Cl}(1.95,4.06), P<0.001]$ were higher in patients with postoperative AKI than that without AKI.

Conclusions The incidence of AKI after TAAD repair surgery was high, and it increased the in-hospital and 30-day mortality. Reducing cardiopulmonary bypass time and RBC transfusions perioperatively, especially in elderly or patients with high body mass index, or patients with renal malperfusion preoperatively were important to prevent AKI after TAAD repair surgery.

\section{Systematic review registration number: INPLASY 202060100.}

\section{Background}

Acute Type A aortic dissection (TAAD) is the most critical condition in cardiovascular diseases with poor outcomes ${ }^{[1]}$. Despite continuous improvement of surgical techniques and medical management, the morbidity and mortality after TAAD repair surgery still remain high ${ }^{[2]}$. Acute kidney injury (AKI) is one of the most common complications after TAAD repair surgery, with an incidence of $18-67 \%{ }^{[3,4]}$, which is higher than other cardiac surgeries ${ }^{[5]}$. What's more, postoperative AKI in TAAD increases in-hospital mortality, short-term mortality, long-term mortality, and major complications ${ }^{[5-7]}$. However, no reliable drugs or specific treatments are available to prevent or cure AKI, except renal replacement therapy (RRT) ${ }^{[8]}$. But in fact, the prognosis of RRT after TAAD repair surgery is not ideal ${ }^{[9]}$. Therefore, early identification of risk factors for postoperative AKI are of great importance for decreasing the incidence of AKI and improving the outcomes of patients undergoing TAAD repair surgery. At present, some studies have analyzed the risk factors for AKI after TAAD repair surgery ${ }^{[5,6,10-18]}$, but only one study was multicentric ${ }^{[14]}$. Besides, the sample size in most studies was not large enough and the results were inconsistent among different studies. In addition, there is no meta-analysis about risk factors for AKI after TAAD repair surgery, except one meta-analysis investigated the independent risk factors for postoperative AKI and the impact of AKI on 30-day postoperative outcomes in patients with TAAD ${ }^{[7]}$. Howerer, the retrieval strategy of this meta-analysis focused more on the impact of AKI on postoperative complications and mortality. Moreover, there was some heterogeneity in the included articles, and the retrieval period was only from 2011 to 2017 whose time range was too narrow. Therefore, we conducted a systematic review and meta-analysis to performe a more completed retrieval and a more focused analysis of risk factors for AKI after TAAD repair surgery so as to fill and improve the research gaps in this field. The primary purpose of this meta-analysis was to comprehensively investigate the risk factors for AKI after TAAD repair surgery with multi-center data. The second purpose was analyzing the combined incidence of AKI and its impact on mortality after TAAD repair surgery. In this way, we try to provide better guidance for early identification and management of postoperative AKI in TAAD.

\section{Materials And Methods}

Study protocol: This systematic review and meta-analysis was conducted using a prespecified protocol and was in accordance with the Preferred Reporting Items for Systematic Reviews and Meta-analyses guidelines.

Search strategy[Studies on risk factors for AKI after TAAD repair surgery were searched without language restriction from PubMed, Embase, Cochrane library and Web of science ranging from inception of the databases to June 2021. The subject words of medical subject heading (MeSH) terms were "Aneurysm, Dissection" AND "Acute Kidney Injury" AND "Risk Factors". The search strategy was subject words combined with free words, and the search strategy in Pubmed was provided in Supplymentary materials 1). At the same time, the ralated references of the included studies were manually searched to identify potential literature that met the inclusion criteria. If necessary, authors would be contacted for detailed data.

Inclusion criteria: (1) Study type: randomized controlled trials, prospective and retrospective cohort studies of risk factors for AKI after TAAD repair surgery; (2) Participants: Patients older than 18 years old who were diagnosed with TAAD by computed tomography angiography of the thoracic and abdominal aorta and underwent TAAD repair surgery; (3) Research contents: risk factors for AKI after TAAD repair surgery. The definitions of all risk factors were similar. The diagnostic criteria of AKI included three most commonly used criteria, that is RIFLE (Risk, Injury, Failure, Loss of function, End-stage renal disease), AKIN (Acute Kidney Injury Network) and KDIGO (Kidney Disease Improving Global Outcomes). The AKI was diagnosed when the value of postoperative serum creatinine ( $\mathrm{sCr}$ ) was 1.5-fold higher than the baseline level or an increased value of $0.3 \mathrm{mg} / \mathrm{dl}$ within 48 hours postoperatively. (4) Outcome indicators: The multivariate logistic regression analysis was adopted and the odds ratio (OR) and its $95 \%$ confidence interval (Cl) of the risk factors were provided in the original studies. 
Exclusion criteria: (1) Literature review, conference abstract, case report or unpublished studies; (2) The full text could not be obtained, the statistical method was improperly applied, the original data was incomplete, or the OR and 95\% Cl could not be extracted; (3) Repeated literature; (4) The definition of risk factor was significantly different from most other studies.

Studies screening, data extraction and study quality evaluation[Two investigators (Lei Wang and Yi Dong) independently completed the study screening, data extraction and study quality evaluation. In case of doubt or disagreement, the two investigators should discuss and decide together or consult the third investigator (Xiaochai Lv). Data were extracted including the first author, publication year, study country, study type, number of cases, risk factors and other relevant data. The Newcastle-Ottawa Scale (NOS) was used to evaluate study quality, and a total score of greater than 6 stars was considered of high quality.

Statistical analysisロStata 16.0 software was used for statistical analysis. The OR or rate ratio (RR) and its $95 \% \mathrm{Cl}$ were used as effect indicators. The heterogeneity of the included studies was tested by $Q$ test and $P$. If $P<50 \%$ and $P>0.1$, it suggested that there was no heterogeneity among the studies, and fixed effect model was used for analysis. On the contrary, If $P>50 \%$ or $P<0.1$, it suggested that the studies were heterogeneous, and the sensitivity analysis or subgroup analysis was used to find the source of heterogeneity. At last, if the source of heterogeneity could not be found or the heterogeneity was very little, the random effect model was used for analysis. The funnel plot, Egger's test and Begg's test were used to detect publication bias if the number of included studies was more than 3. If $P 0.1$ in Begg's test and Egger's test, it indicated that there was no publication bias between studies. $P<0.05$ was considered statistically significant.

\section{Results}

Literature search process. As shown in Figure 1, a total of 220 studies were obtained in the initial search, and 11 studies were finally included.

Characteristics and literature quality evaluation of the included studies. As shown in Table 1, the included studies involved a total of 4156 patients. Alltogether 18 risk factors were involved, and five of them, that is advanced age, long cardiopulmonary bypass (CPB) time, high body mass index (BMI), perioperative red blood cell (RBC) volume transfused and preoperative renal malperfusion, were mentioned in two or more studies, which were further analyzed in this metaanalysis. The NOS scale was used to evaluate the literature quality, and all studies had above 6 stars, thus all of them were of high quality.

The incidence of AKI and continuous renal replacement therapy (CRRT) after TAAD repair surgery. The conbined incidence of AKI and CRRT after TAAD repair surgery was $56.0 \%$ (range, $46.0 \%-66.0 \%$ ) and $11.0 \%$ (range, 9.0\%-13.0\%), respectively, which was similar to the previous studies. The forest plot was shown in Supplementary materials 2 .

\section{The risk factors for AKI after TAAD repair surgery.}

1. Advanced age. Four studies ${ }^{[10-12,14]}$ suggested that the advanced age was a risk factor for AKI after TAAD repair surgery, but the forest plot (Supplementary materials 3 ) showed that the heterogeneity was obvious $\left(P^{2}=91.4 \%, P=0.000\right)$. Then we found that the study of "Qiu 2015 " and "Fang 2019" might be the source of heterogeneity through the forest plot and sensitivity analysis (Supplementary materials 4), and after we excluded this two studies, there was no heterogeneity between studies $\left(P=0.653, P^{2}=0 \%\right)$ (Figure 2). Thus the fixed effect model was used, and the combined OR ( $95 \% \mathrm{Cl}$ ) was $1.32(1.19,1.47)(Z=5.18, P<0.001)$, so we concluded that the advanced age was a risk factor for AKI after TAAD repair surgery.

2. Long CPB time. Eight studies ${ }^{[5,6,10-14,18]}$ suggested that long CPB time was a risk factor for AKI after TAAD repair surgery, but the forest plot (supplementary materials 5$)$ showed obvious heterogeneity $\left(P^{2}=78.2 \%, P=0.000\right)$. Since the definition of CPB time in the study of "Qiu 2015 " and "Roh 2012" was "CPB time>180 minutes" which was different from other studies, subgroup analysis was further conducted according to the different group of " CPB time $>180$ minutes" and "long CPB time" (Figure 3). The subgroup of " CPB time> 180 minutes" showed no heterogeneity $(R=0, P 0.1)$, and the combined OR $(95 \% \mathrm{Cl})$ was $4.88(2.05,11.59)(Z=3.59, P<0.001)$, so we concluded that the CPB time $>180$ minutes was a risk factor for AKI after TAAD repair surgery.

3. The RBC volume transfused perioperatively. Four studies ${ }^{[10,14,17,18]}$ suggested that the RBC volume transfused perioperatively was a risk factor for AKI after TAAD repair surgery, but its definition in the study of "Qiu 2015" was RBC transfusion $>10$ units which was different from other studies. So we only included three studies ${ }^{[14,17,18]}$. The forest plot (Figure 4$)$ showed only a little heterogeneity which was acceptable $\left(P^{2}=54.5 \%, P>0.1\right)$. The combined OR $(95 \% \mathrm{Cl})$ was $1.13(1.03,1.24)(Z=2.66, P 0.01)$, so we concluded that the RBC volume transfused perioperatively was a risk factor for AKI after TAAD repair surgery.

4. High BMI. Six studies ${ }^{[5,11,12,14,16,18]}$ suggested that high BMI was a risk factor of AKI after TAAD repair surgery, but the forest plot (Supplementary materials 6$)$ showed obvious heterogeneity $\left(P^{2}=85.6 \%, P=0.000\right)$. Therefore, sensitivity analysis (Supplementary materials 7$)$ was continued and it found that "Fang 2019" and "Helgason 2020" were the main causes of heterogeneity. After deletion this two studies, forest plot (Figure 5) was performed again and the results showed no heterogeneity $(R=27 \%, P=0.25)$. Therefore, the fixed effect model was adopted for combination analysis, and the combined $\mathrm{OR}$ $(95 \% \mathrm{Cl})$ was $1.22(1.18,1,27)(Z=5.39, P 0.001)$. The publication bias was evaluated by the funnel plot and it showed symmetric (Supplementary materials 8$)$, and the Begg's test $(P=0.308>0.1)$ as well as the Egger's test $(P=0.381>0.1)$ indicated that there was no publication bias between these four studies. So it concluded that high BMI was a risk factor for AKI after TAAD repair surgery.

5. Preoperative renal malperfusion. Two studies ${ }^{[5,14]}$ suggested that preoperative renal malperfusion was a risk factor of AKI after TAAD repair surgery, and the forest plot (Figure 6) showed no heterogeneity $\left(P^{2}=8 \%, P=0.297\right)$. Therefore, the fixed effect model was adopted for combination analysis. The combined OR $(95 \% \mathrm{Cl})$ was $5.32(2.92,9.71)(Z=5.45, P$ 0.001), so it concluded that preoperative renal malperfusion was a risk factor for AKI after TAAD repair. 
The impact of AKI after TAAD repair surgery on mortality. The in-hospital mortality in patients with postoperative AKI was $20 \%$ (range, $16 \%-24 \%, P<0.001$ ), (Heterogeneity test: $P^{2}=37.9 \%, P=0.2$ ) (Supplementary materials 9 ). The 30 -days mortality after surgery in patients with postoperative AKI was $16 \%$ (range, $14 \%-19 \%, P<0.001)$, (Heterogeneity test: $\left.P^{2}=47.3 \%, P=0.128\right)$ (Supplementary materials 10$)$. The (RR $(95 \% \mathrm{Cl})$ ) of in-hospital mortality in patients with and without postoperative AKI was $2.50(1.82,3.44, P<0.001), P<0.001$.(Heterogeneity test: $P=0, P=0.704)$ (Supplementary materials 11$)$. The rate ratio (RR) and its $95 \% \mathrm{Cl}$ of 30 -days mortality in patients with and without postoperative AKI was $2.81(1.95,4.06, P<0.001)$ (Heterogeneity test: $P^{2}=0, P=0.386$ ) (Supplementary materials 12).

\section{Discussion}

Postoperative AKI is a common complication after TAAD repair surgery. This meta-analysis comprehensively analyzed that the combined incidence of postoperative AKI after TAAD repair surgery was $56.0 \%$, which was consistent with previous range of $18-67 \%$ [3, 4$]$. The previous range was relatively wide since different diagnostic criteria was used for AKI and heterogeneous TAAD patients underwent different repair surgery, resulting in different incidence of postoperative AKI in different studies. However, in our meta-analysis, the most up-to-date and widely recognized diagnostic criteria with relatively lower diagnostic threshold of AKI, that is KDIGO, was used in most studies, and the definition of postoperative AKI was same even though some studies used the diagnostic criteria of AKIN or RIFLE. Besides, in our meta-analysis, most patients with TAAD underwent total arch replacement repair surgery with deep hypothermia circulatory arrest (DHCA). Thus, most patients was relatively homogeneous and the slightly higher incidence of postoperative AKI of $56 \%$ was reasonable. The in-hospital mortality and 30-days mortality after surgery in patients with postoperative AKI was $16 \%$ and $20 \%$, respectively, and patients with postoperative AKI had a significantly increased risk of death (almost 2.5-2.8 fold) in hospital and 30 day postoperatively, which was consistent with the fact that AKI after TAAD repair surgery seriously affects the mortality of patients ${ }^{[5]}$. Under the circumstances, early identification of risk factors for AKI after TAAD repair surgery and preventing postoperative $\mathrm{AKI}$ are of great importance in improving outcomes.

The studies included in this meta-analysis showed that the risk factors for AKI after TAAD repair surgery involved 18 items, but some risk factors were only concluded in one study making difficult to do further statistic. Hence only five risk factors were involved in this meta-analysis finally, and all of them had statistical significance. That is to say, the advanced age, CPB time > 180 minutes, more volume of perioperative RBC transfused, high BMI, and preoperative renal malperfusion were risk factors for postoperative AKI after TAAD repair surgery.

Our study showed that the advanced age was a combined risk factor for AKI after TAAD repair surgery. This was consistent with the meta-analysis ${ }^{[7]}$ and previous studies ${ }^{[10,12,14]}$. Helgason et al. and Zhou et al. found that for every 10 years of the increased age, the incidence of AKI after TAAD repair surgery is increased by 1.3 to 1.37 times ${ }^{[12,14]}$, which may be owing to the poor basic renal function of elderly patients and their poor ischemic tolerance to surgery and DHCA, leading to the occurrence of postoperative AKI easily. It is easier to understand that kidney function gradually decreases with age ${ }^{[19]}$. Elderly patients who developed AKI had a higher number of hospitalizations (underlying frailty), were more likely to progress to chronic kidney disease and to be affected by other non-renal pathologies (associated comorbidities) ${ }^{[20]}$. On the contrary, Amano Kentaro et al. ${ }^{[21]}$ suggestted that younger patients are at a greater risk of postoperative AKI. The reason may be that some young patients with atherosclerosis or calcification of aortic dissection and the dissection can easily and widely tear from proximal aortic root to distal iliac artery or femoral artery, leading to more patients need total arch replacement repair, and resulting in an increased incidence of postoperative AKI after TAAD repair surgery. But combined with our results, we are more likely to believe that the advanced age is a risk factor for postoperative AKI. In a word, adequate attention should be paid to renal function of elderly patients after TAAD repair surgery.

Our study also showed that long CPB time, especially CPB time > 180 minutes was a combined risk factor for AKI after TAAD repair surgery, which was also consistent with previous meta-analysis ${ }^{[22]}$ and most studies ${ }^{[5,6,10-14,18,23]}$. Roh et al. ${ }^{[6]}$ found that the risk of AKI development after TAAD repair surgery is 4 times in patients with CPB time $>180$ minutes than in patients with CPB time $<120$ minutes. The CPB time $>180$ minutes not only increases 3 to 4 times of the risk of postoperative AKI, but also significantly increases the in-hospital mortality ${ }^{[23]}$. The increased risk odds of 3 to 4 times were similar to our study result. For Debakey type I aortic dissection, the incidence of AKI is increased by $17.1 \%$ for every 10 minutes added of CPB time, and after adjusting for the potential confounding factors by propensity score matching method, the results still remain statistic significant ${ }^{[13]}$. The underlying mechanism of the relationship between CPB time and AKI is unclear. The central pathogenesis of AKI during CPB were the reduced renal perfusion pressure, activation of proinflammatory mediators, direct nephrotoxicity and hemolysis ${ }^{[24]}$, and all these factors might be aggravated as CPB time extends. Longer CPB time and transfusions of autologous blood products from cell salvage devices may cause high levels of hemocytocatheresis and hemolysis during surgery ${ }^{[25]}$. Mamikonian et al. ${ }^{26]}$ also found that significant hemolysis occurs during cardiac surgery with CPB, which is related to the development of postoperative AKI. Therefore, reducing CPB-induced hemolysis and removing the free hemoglobin by endogenous mechanisms can minimize the toxic effect of acute hemolysis and therefore reduce the incidence of postoperative AKI. In addition, L. Lannemyr et al. ${ }^{[27]}$ performed a research on the association between the renal tubular injury and $\mathrm{CPB}$, and they found that the renal tubular cell injury is detected with a peak biomarker increased early after onset of CPB during cardiac surgery. The extent of renal tubular injury is independently associated with CPB time and rewarming quality. Therefore, shortening CPB time and avoiding hypothermia can decrease renal tubular cell injury. The CPB time is a modifiable factor. Qiu et al. ${ }^{[10]}$ found that ascending aortic replacement combined with open triple-branched stent graft placement can reduce the occurrence of postoperative AKI and protect renal function via reducing CPB time. Thus, in patients with TAAD, reducing hemolysis, enhancing blood protection, simplifying surgical techniques, and shortening operation and CPB time, are considered to be important in protecting renal function and reducing the incidence of postoperative AKI.

The RBC volume transfused was also a combined risk factor for postoperative AKI. Qiu et al. ${ }^{[10]}$ found that intraoperative and early postoperative RBC

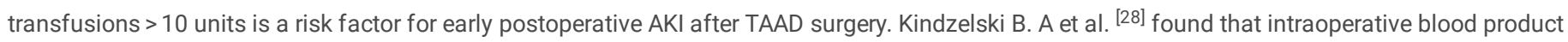
transfusions are independently associated with an increased odds of developing AKI after cardiac surgery. Syed S. found that RBC transfusions above a threshold increases the incidence of postoperative complications and hospital length of stay among patients undergoing TAAD repair surgery [29]. The 
possible mechanism was that RBC transfusions will cause proinflammatory reaction and increase oxidative stress, and result in the end-organ damage and adverse immunomodulatory effect on T-cell function ${ }^{[30}$. Besides, RBC hemolysis occurs during RBC storage and following transfusions can lead to increased free hemoglobin and iron which will cause microcirculation dysfunction [31]. In addition, the need for RBC transfusions is also an indirect indicator of surgery complexity and more bleeding. Therefore, it is recommended to reduce operation-related bleeding and minimize RBC transfusions perioperatively in TAAD repair surgery.

High BMI was a combined risk factor for AKI after TAAD repair surgery in our study, which was consistent to the previous meta-analysis ${ }^{[7]}$.The previous studies found that high BMI was an independent predictor of the AKI development in patients undergoing TAAD repair surgery ${ }^{[32]}$ as well as cardiovascular surgery with $\mathrm{CPB}{ }^{[33]}$. High BMI may be associated with AKI development in critically ill patients ${ }^{[34]}$ and is also a risk factor of AKI in noncardiac surgery ${ }^{[35]}$. The association between high BMI and risk of AKI development during CPB could be multifactorial. First, obesity leads to glomerular hyperperfusion and hyperfiltration, and leads to deterioration of renal function called obesity-related glomerulopathy ${ }^{[36]}$. Second, obesity can increase the hemodynamic and

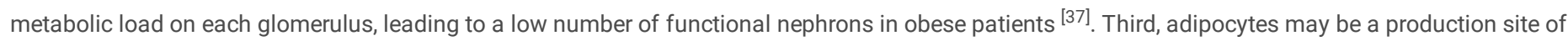
activated inflammatory cytokines and oxidative stress in obese patients. Increased oxidative stress can contribute to detrimental changes in the glomeruli [38]. All glomeruli lesions above can be increased by the lower kidney perfusion pressure, proinflammatory cytokines and microemboli during CPB. Fourth, excess abdominal fat increases abdominal pressure, which may cause renal dysfunction from both renal venous congestion and poor arterial perfusion. Fifth, as a component of metabolic syndrome, obesity is also a significant risk factor for cardiovascular disease, hypertension, and diabetes mellitus, which may provide a vulnerable physiological reserve to handle the hypoperfusion of kidney during surgery with CPB.

However, some study did not found that high BMI was a risk factor for AKI after TAAD repair surgery. Besides, Liu A et al. found that underweight Asian patients are susceptible to AKI in acute hospital settings ${ }^{[39]}$. The reason might be that malnutrition was independently associated with increased risks of AKI, morbidity, and mortality. Besides, nowdays, some studies found obesity paradox in many severe diseases. It refers to the phenomenon that being overweight and moderately obese was actually associated with superior clinical outcomes and a lower risk of all-cause mortality [40]. It can be presumed that obesity provides substantial energy resources and protective effects, and negates the harmful effects caused by inflammation, infection, and cardiovascular events. Despite this phenomenon, obesity paradox has not been found in obese paitents ungergoing TAAD repair surgery. Above all, for obese patients undergoing TAAD surgery, we should pay close attention to postoperative renal function.

Preoperative renal malperfusion was the last risk factor of postoperative AKI, and it might be related to organ hypoperfusion caused by cardiac tamponade and cardiogenic shock, or renal artery involvement owing to aortic dissection. The definition of renal malperfusion was impressionable and inconsistent, including computerized tomography (CT) manifestations in renal and/or with an increase of sCr value. Since a significant decrease in nephrons function (more than $50 \%$ ) is associated with clinically elevated $\mathrm{sCr}$ value, the $\mathrm{sCr}$ is not a sensitive indicator of renal impairment. As a resut, most studies did not found that preoperative $\mathrm{sCr}$ value is a risk factor for postoperative AKI. On the contrary, Helgason et al. ${ }^{[14]}$ found that the renal malperfusion is an independent risk factor for postoperative $\mathrm{AKI}$, and $69 \%$ of patients with preoperative signs of renal malperfusion developed AKI, usually be the most severe AKI stage. In the German Registry for Acute TAAD, Czerny and associates have shown that preoperative renal malperfusion increased the risk of postoperative renal ischemia by 11 times ${ }^{[41]}$. The reason between preoperative renal malperfusion and postoperative AKI is that the former leads to impaired preoperative renal function and the decrease of renal ischemia tolerance. Besides, the surgery with DHCA will lead to abnormal distribution of renal blood flow and increase renal vascular resistance ${ }^{[21]}$, thus increasing the incidence of postoperative AKI. However, some study did not find that the preoperative renal malperfusion is a risk factor of postoperative AKI. It may speculate that the improved perfusion of the kidneys postoperatively may be sustained through the false lumen or due to improved blood flow through the true lumen as a result of the surgical repair. Another reason may be that the information about renal malperfusion was missing for $13 \%$ of patients, and it is possible that some patients with impaired renal blood flow were not classified as renal malperfusion due to the different quality of the CT scans ${ }^{[14]}$. This possibly resulted in an underestimation of the true incidence and severity of AKI in these patients. According to our result, we should pay more attention to the patients with preoperative renal malperfusion.

- In the patients included in our study, DHCA is not independently associated with postoperative AKI. These intuitively asymmetric results may be explained by the protective effects of DHCA on organ function, which counterbalance the kidney damage expected from prolonged CPB. Besides, compared with other cardiac procedures, the repair surgery is more complex, the CPB time is longer, the RBC transfusions is more needed, and the preoperative renal malperfusion is more common in TAAD repair surgery. In this way, the effects of these factors are even more pronounced than the factor of DHCA. But other investigations identifified that DHCA was an independent risk factor for AKI ${ }^{[42]}$. These discrepant findings may be explained by the confounding factors introduced by heterogeneous patient groups.

\section{Conclusions}

The incidence of AKI after TAAD repair surgery was high, and it increased the in-hospital and 30-day mortality. Among the risk factors for AKI after TAAD repair surgery in this meta-analysis, the advanced age, high BMI and preoperative renal malperfusion due to the aortic dissection was unmodifiable, while CPB time and RBC volume transfused perioperatively was modifiable. Thus, improving surgical techniques and reducing the CPB time, and decreasing the using of RBC transfusions perioperatively can reduce the incidence of AKI after TAAD repair surgery and improve the clinical outcome of the patients, especially in eldly patients, patients with higher BMI, or patients with renal malperfusion preoperatively. Early identification of these risk factors enables clinicians to closely monitor patients and initiate effificient preventive and therapeutic strategies to reduce the incidence of AKI.

\section{Strengths And Limitations Of This Study}


This meta-analysis performed a completed retrieval and a more focused analysis of risk factors for AKI after TAAD repair surgery, as well as the combined incidence of postoperative AKI and its impact on the in-hospital mortality and 30-day mortality through multicenter-data for the first time. Besides, the diagnostic criteria of AKI in most included studies was KDIGO which is the latest one, and almost all patients in the included studies underwent TAAD repair surgery with DHAC, thus the accuracy and extensibility of the results were improved. But there still be some limitations about this study. One is that some risk factors are only concluded in one study, so no further statistical analysis was performed. As a result, some risk factors may be overlooked. The other one is that this study only analyzed the impact of postoperative AKI on short-term mortality in TAAD, and no long-term mortality and complications as well as the impact of individual risk factor on mortality were analyzed. In addition, specific value of BMI contributing to AKI was not analyzed further. Moreover, almost half studies included were retrospective, so more randomized controlled trials are needed to identify risk factors and appropriate strategies to improve the outcomes of patients undergoing TAAD repair surgery.

\section{Abbreviations}

AKI: Acute kidney injury; TAAD: type A aortic dissection; RBC: red blood cell; OR: odds ratio; Cl: confidence interval; RR: rate ratio; RRT: renal replacement therapy; MeSH: medical subject heading; RIFLE: Risk, Injury, Failure, Loss of function, End-stage renal disease; AKIN: Acute Kidney Injury Network; KDIGO: Kidney Disease Improving Global Outcomes; sCr: serum creatinine; NOS: Newcastle-Ottawa Scale; CPB: cardiopulmonary bypass; BMI: body mass index; CRRT: continuous renal replacement therapy; DHCA: deep hypothermia circulatory arrest; CT: computerized tomography.

\section{Declarations}

Ethics approval and consent to participate: All procedures performed in studies involving human participants were in accordance with the 1964 Helsinki Declaration. The study was approved by the Bioethics Committee of the Union Hospital of Fujian Medical University. Since the retrospective nature of the study, patient consent for inclusion was waived.

Consent for publication: Not applicable.

Availability of data and materials: The search strategy relevant to the study are uploaded as online supplementary information.

Competing interests: The authors declare that they have no competing interests.

Funding: This study was funded by Sponsored by Fujian provincial health technology project (2020QNB020) and the National Natural Science Foundation of China (U2005202).

Authors' contributions: LW conceived and wrote the manuscript. GDZ, LXV, YD, XFD reviewed the manuscript, LWC read and proofed the manuscript. All authors read and approved the final manuscript.

Acknowledgement: Not applicable.

\section{References}

1. Takagi $\mathrm{H}$, Umemoto T, Group A. A meta-analysis of total arch replacement with frozen elephant trunk in acute type A aortic dissection. Vasc Endovascular Surg. 2016;50:33-46.

2. Castrovinci S, Pacini D, Di Marco L, Berretta P, Cefarelli M, Murana G, et al. Surgical management of aortic root in type A acute aortic dissection: a propensity-score analysis. Eur J Cardiothorac Surg. 2016;50:223-9.

3. Mori Y, Sato N, Kobayashi Y, Ochiai R. Acute kidney injury during aortic arch surgery under deep hypothermic circulatory arrest. J Anesth. 2011;25:799804.

4. Kim WH, Lee JH, Kim E, Kim G, Kim HJ, Lim HW. Can We Really Predict Postoperative Acute Kidney Injury after Aortic Surgery? Diagnostic Accuracy of Risk Scores Using Gray Zone Approach. Thorac Cardiovasc Surg. 2016;64:281-9.

5. Ko T, Higashitani M, Sato A, Uemura Y, Norimatsu T, Mahara K, et al. Impact of Acute Kidney Injury on Early to Long-Term Outcomes in Patients Who Underwent Surgery for Type A Acute Aortic Dissection. Am J Cardiol. 2015;116:463-8.

6. Roh GU, Lee JW, Nam SB, Lee J, Choi JR, Shim YH. Incidence and Risk Factors of Acute Kidney Injury After Thoracic Aortic Surgery for Acute Dissection. Ann Thorac Surg. 2012;94:766-71.

7. Wang J, Yu W, Zhai G, Liu N, Sun L, Zhu J. Independent risk factors for postoperative AKI and the impact of the AKI on 30-day postoperative outcomes in patients with type A acute aortic dissection: an updated meta-analysis and meta-regression. J Thorac Dis. 2018;10:2590-8.

8. Joannidis M, Druml W, Forni LG, Groeneveld ABJ, Honore PM, Hoste E, et al. Prevention of acute kidney injury and protection of renal function in the intensive care unit: update 2017: Expert opinion of the Working Group on Prevention, AKI section, European Society of Intensive Care Medicine. Intensive Care Med. 2017;43:730-49.

9. Wang ZG, Ge M, Chen T, Chen C, Zong QY, Lu LC, et al. Independent risk factors and the long-term outcomes for postoperative continuous renal replacement treatment in patients who underwent emergency surgery for type a acute aortic dissection. J Cardiothorac Surg. 2020;15:100.

10. Qiu ZH, Chen LW, Cao H, Zhang GC, Xu F, Chen Q. Analysis of Risk Factors for Acute Kidney Injury after Ascending Aortic Replacement Combined with Open Placement of Triple-Branched Stent Graft in Type A Aortic Dissection: A New Technique versus the Traditional Method in a Single Chinese Center. 
Med Sci Monit. 2015;21:674-80.

11. Fang ZR, Wang GY, Liu Q, Zhou H, Zhou S, Lei GY, et al. Moderate and deep hypothermic circulatory arrest has a comparable effect on acute kidney injury after total arch replacement with frozen elephant trunk procedure in type A aortic dissection. Interact Cardiovasc Thorac Surg. 2019;29:130-6.

12. Zhou H, Wang G, Yang L, Shi S, Li J, Wang M, et al. Acute Kidney Injury After Total Arch Replacement Combined With Frozen Elephant Trunk Implantation: Incidence, Risk Factors, and Outcome. J Cardiothorac Vasc Anesth. 2018;32:2210-7.

13. Xu S, Liu J, Li L, Wu Z, Li J, Liu Y, et al. Cardiopulmonary bypass time is an independent risk factor for acute kidney injury in emergent thoracic aortic surgery: a retrospective cohort study. J Cardiothorac Surg. 2019;14:90.

14. Helgason D, Helgadottir S, Ahlsson A, Gunn J, Hjortdal V, Hansson EC, et al. Acute Kidney Injury After Acute Repair of Type A Aortic Dissection. Ann Thorac Surg. 2021;111:1292-8.

15. Wang Z, Ge M, Chen T, Chen C, Zong Q, Lu L, et al. Acute kidney injury in patients operated on for type A acute aortic dissection: incidence, risk factors and short-term outcomes. Interact Cardiovasc Thorac Surg. 2020;31:697-703.

16. Liu T, Fu Y, Liu J, Liu Y, Zhu J, Sun L, et al. Body mass index is an independent predictor of acute kidney injury after urgent aortic arch surgery for acute DeBakey Type I aortic dissection. J Cardiothorac Surg. 2021;16:145.

17. Liu Y, Shang Y, Long D, Yu L. Intraoperative blood transfusion volume is an independent risk factor for postoperative acute kidney injury in type A acute aortic dissection. BMC Cardiovasc Disord. 2020;20:446.

18. Li LJ, Zhou JJ, Hao XC, Zhang WY, Yu DS, Xie Y, et al. The Incidence, Risk Factors and In-Hospital Mortality of Acute Kidney Injury in Patients After Surgery for Acute Type A Aortic Dissection: A Single-Center Retrospective Analysis of 335 Patients. Front Med. 2020;7:557044.

19. O'Sullivan ED, Hughes J, Ferenbach DA. Renal aging: causes and consequences. J Am Soc Nephrol. 2017;28:407-17.

20. Formica M, Politano P, Marazzi F, Tamagnone M, Serra I, Marengo M, et al. Acute Kidney Injury and Chronic Kidney Disease in the Elderly and Polypharmacy. Blood Purif. 2018;46:332-6.

21. Amano K, Takami Y, Ishikawa H, Ishida M, Tochii, Akita K. Lower body ischaemic time is a risk factor for acute kidney injury after surgery for type $A$ acute aortic dissection. Interact Cardiovasc Thorac Surg. 2020;30:107-12.

22. Kumar AB, Suneja M, Bayman EO, Weide GD, Tarasi M. Association Between Postoperative Acute Kidney Injury and Duration of Cardiopulmonary Bypass: A Meta-Analysis. J Cardiothorac Vasc Anesth. 2012;26:64-9.

23. Harel Z, Bell CM, Dixon SN, McArthur E, James MT, Garg AX, et al. Predictors of progression to chronic dialysis in survivors of severe acute kidney injury a competing risk study. BMC Nephrol. 2014;15:114.

24. Billings FT, Yu C, Byrne JG, Petracek MR, Pretorius M. Heme oxygenase-1 and acute kidney injury following cardiac surgery. Cardiorenal Med. 2014;4:1221.

25. Vercaemst L. Hemolysis in cardiac surgery patients undergoing cardiopulmonary bypass: a review in search of a treatment algorithm. $\mathrm{J}$ Extra Corpor Technol. 2008;40:257-67.

26. Mamikonian LS, Mamo LB, Smith PB, Koo J, Lodge AJ, Turi JL. Cardiopulmonary bypass is associated with hemolysis and acute kidney injury in neonates, infants, and children. Pediatr Crit Care Med. 2014;15:e111-9.

27. Lannemyr L, Lundin E, Reinsfelt B, Bragadottir G, Redfors B, Oras J, et al. Renal tubular injury during cardiopulmonary bypass as assessed by urinary release of N-acetyl-ss-D glucosaminidase. Acta Anaesthesiol Scand. 2017;61:1075-83.

28. Kindzelski BA, Corcoran P, Siegenthaler MP, Horvath KA. Postoperative acute kidney injury following intraoperative blood product transfusions during cardiac surgery. Perfusion. 2018;33:62-70.

29. Naeem SS, Sodha NR, Sellke FW, Ehsan A. Impact of Packed Red Blood Cell and Platelet Transfusions in Patients Undergoing Dissection Repair. J Surg Res. 2018;232:338-45.

30. Koch CG, Li L, Duncan Al, Mihaljevic T, Cosgrove DM, Loop FD, et al. Morbidity and mortality risk associated with red blood cell and blood-component transfusion in isolated coronary artery bypass grafting. Crit Caer Med. 2006;34:1608-16.

31. Karkouti K. Transfusion and risk of acute kidney injury in cardiac surgery. Br J Anaesth. 2012;109:i29-38.

32. Zhao H, Pan X, Gong Z, Zheng J, Liu YM, Zhu JM, et al. Risk factors for acute kidney injury in overweight patients with acute type A aortic dissection: A retrospective study. J Thorac Dis. 2015;7:1385-90.

33. Shi N, Liu K, Fan Y, Yang L, Zhang S, Li X, et al. The Association Between Obesity and Risk of Acute Kidney Injury After Cardiac Surgery. Front Endocrinol (Lausanne). 2020;11:534294.

34. Ju S, Lee TW, Yoo JW, Lee SJ, Cho YJ, Jeong YY, et al. Body Mass Index as a Predictor of Acute Kidney Injury in Critically III Patients: A Retrospective Single-Center Study. Tuberc Respir Dis (Seoul). 2018;81:311-8.

35. Zhou J, Lyu L, Zhu L, Liang YX, Dong H, Chu HC, et al. Association of overweight with postoperative acute kidney injury among patients receiving orthotopic liver transplantation: an observational cohort study. BMC Nephrol. 2020;21:223.

36. Suneja M, Kumar AB. Obesity and perioperative acute kidney injury: A focused review. J Crit Care. 2014;29:694.e1-6.

37. Hostetter TH, Olson JL, Rennke HG, Venkatachalam MA, Brenner BM. Hyperfiltration in remnant nephrons: a potentially adverse response to renal ablation. J Am Soc Nephrol. 2001;12:1315-25.

38. Chander PN, Gealekman O, Brodsky SV, Elitok S, Tojo A, Crabtree M, et al. Nephropathy in Zucker diabetic fat rat is associated with oxidative and nitrosative stress: prevention by chronic therapy with a peroxynitrite scavenger ebselen. J Am Soc Nephrol. 2004;15:2391-403. 
39. Liu AYL, Wang J, Nikam M, Lai BC, Yeoh LY. Low, rather than High, Body Mass Index Is a Risk Factor for Acute Kidney Injury in Multiethnic Asian Patients: A Retrospective Observational Study. Int J Nephrol. 2018;2018:3284612.

40. Amundson DE, Djurkovic S, Matwiyoff GN. The obesity paradox. Crit Care Clin. 2010;26:583-96.

41. Czerny M, Schoenhoff F, Etz C, Englberger L, Khaladj N, Zierer A, et al. The impact of preoperative malperfusion on outcome in acute type A aortic dissection: results from the GERAADA Registry. J Am Coll Cardiol. 2015;65:2628-35.

42. Gaudino M, Luciani N, Giungi S, Caradonna E, Nasso G, Schiavello R, et al. Different profifiles of patients who require dialysis after cardiac surgery. Ann Thorac Surg. 2005;79:825-9.

\section{Tables}

Table 1 Characteristics and literature quality evaluation of the included studies

${ }^{1}$ Quality Assessment Newcastle-Ottawa scale: S: Selection; C: Comparability; O: Outcome.

AKI: acute kidney injury, CRRT: continuous renal replacement therapy; RIFLE: Risk, Injury, Failure, Loss of function, End-stage renal disease; AKIN: Acute Kidney Injury Network; KDIGO: Kidney Disease Improving Global Outcomes.

\section{Figures}

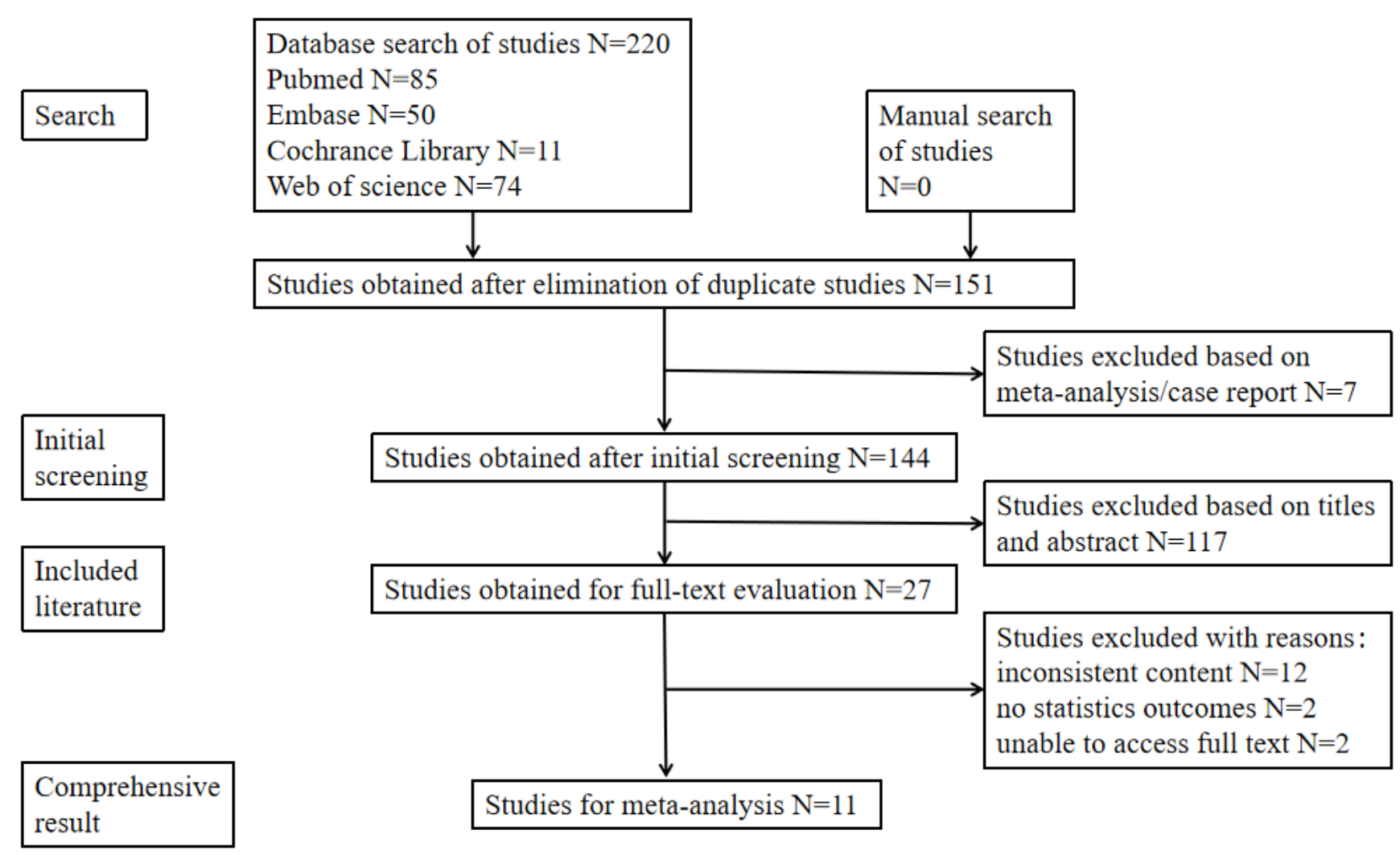

Figure 1

Study screening process. 


\begin{tabular}{|c|c|c|c|c|c|c|c|c|c|c|c|}
\hline $\begin{array}{l}\text { Author, } \\
\text { year }\end{array}$ & Country & Study type & $\begin{array}{l}\text { Diagnosis } \\
\text { of patients }\end{array}$ & $\begin{array}{l}\text { Average } \\
\text { age } \\
\text { (year) }\end{array}$ & $\begin{array}{l}\text { Totle } \\
\text { case }\end{array}$ & $\begin{array}{l}\text { Diagnostic } \\
\text { criteria } \\
\text { of AKI }\end{array}$ & $\begin{array}{l}\text { AKI/ } \\
\text { non-AKI } \\
(n)\end{array}$ & $\begin{array}{l}\text { Incidence } \\
\text { of AKI } \\
\%\end{array}$ & $\begin{array}{l}\text { Incidence } \\
\text { of CRRT } \\
\%\end{array}$ & Risk factors & $\begin{array}{l}\text { S, C, O } \\
1 \\
\text { (Total= } \\
9 \\
\text { scores) }\end{array}$ \\
\hline $\begin{array}{l}\text { Roh, } \\
2012 \text { [6] }\end{array}$ & Korea & $\begin{array}{l}\text { single center } \\
\text { retrospective } \\
\text { study }\end{array}$ & $\begin{array}{l}\text { thoracic } \\
\text { aortic } \\
\text { dissection }\end{array}$ & 55.0 & 98 & RIFLE & $53 / 45$ & 54.0 & 11.0 & $\begin{array}{l}\text { cardiopulmonary } \\
\text { bypass time } \\
>180 \mathrm{~min}, \\
\text { preoperative } \\
\text { serum creatinine } \\
\text { level }\end{array}$ & $3,1,3$ \\
\hline $\begin{array}{l}\text { Qiu, } 2015 \\
\text { [10] }\end{array}$ & China & $\begin{array}{l}\text { single center } \\
\text { retrospective } \\
\text { study }\end{array}$ & $\begin{array}{l}\text { type A } \\
\text { aortic } \\
\text { dissection }\end{array}$ & 51.6 & 155 & AKIN & $56 / 99$ & 36.1 & 6.5 & $\begin{array}{l}\text { advanced age, } \\
\text { aortic arch } \\
\text { replacement } \\
\text { with 4-branched } \\
\text { Dacron graft } \\
\text { combined with } \\
\text { stented elephant } \\
\text { trunk } \\
\text { implantation, } \\
\text { cardiopulmonary } \\
\text { bypass } \\
\text { time>180min, } \\
\text { packed red } \\
\text { blood cells }>10 \mathrm{U}\end{array}$ & $3,1,3$ \\
\hline $\begin{array}{l}\text { Ko, } 2015 \\
\text { [5] }\end{array}$ & Japan & $\begin{array}{l}\text { single center } \\
\text { prospective } \\
\text { cohort study }\end{array}$ & $\begin{array}{l}\text { type A } \\
\text { aortic } \\
\text { dissection }\end{array}$ & 66.4 & 375 & KDIGO & $165 / 210$ & 44.0 & 8.8 & $\begin{array}{l}\text { cardiopulmonary } \\
\text { bypass time, } \\
\text { high body mass } \\
\text { index, } \\
\text { preoperative } \\
\text { renal } \\
\text { malperfusion, } \\
\text { perioperative } \\
\text { sepsis, } \\
\text { perioperative } \\
\text { peak C reactive } \\
\text { protein }\end{array}$ & $3,1,3$ \\
\hline $\begin{array}{l}\text { Zhou, } \\
2018^{[12]}\end{array}$ & China & $\begin{array}{l}\text { single center } \\
\text { prospective } \\
\text { cohort study }\end{array}$ & $\begin{array}{l}\text { thoracic } \\
\text { aortic } \\
\text { dissection } \\
(95 \%)\end{array}$ & 46.5 & 553 & KDIGO & $429 / 124$ & 77.6 & 11.4 & $\begin{array}{l}\text { advanced age, } \\
\text { cardiopulmonary } \\
\text { bypass time, } \\
\text { high body mass } \\
\text { index, male sex }\end{array}$ & $3,1,3$ \\
\hline $\begin{array}{l}\text { Fang, } \\
2019^{[11]}\end{array}$ & China & $\begin{array}{l}\text { single center } \\
\text { prospective } \\
\text { cohort study }\end{array}$ & $\begin{array}{l}\text { type A } \\
\text { aortic } \\
\text { dissection }\end{array}$ & 46.7 & 627 & KDIGO & $473 / 154$ & 75.4 & 10.0 & $\begin{array}{l}\text { advanced age, } \\
\text { cardiopulmonary } \\
\text { bypass } \\
\text { time }>180 \mathrm{~min}, \\
\text { high body mass } \\
\text { index, history of } \\
\text { hypertension }\end{array}$ & $3,1,3$ \\
\hline $\begin{array}{l}\text { Xu, } 2019 \\
{[13]}\end{array}$ & China & $\begin{array}{l}\text { single center } \\
\text { retrospective } \\
\text { study }\end{array}$ & $\begin{array}{l}\text { patients } \\
\text { undergoing } \\
\text { thoracic } \\
\text { aortic } \\
\text { surgery }\end{array}$ & 47.8 & 115 & KDIGO & $61 / 54$ & 53.0 & 14.8 & $\begin{array}{l}\text { cardiopulmonary } \\
\text { bypass time }\end{array}$ & $3,0,3$ \\
\hline $\begin{array}{l}\text { Helgason, } \\
2020^{[14]}\end{array}$ & Iceland & $\begin{array}{l}\text { multicenter } \\
\text { retrospective } \\
\text { cohort } \\
\text { study }\end{array}$ & $\begin{array}{l}\text { type A } \\
\text { aortic } \\
\text { dissection }\end{array}$ & $\begin{array}{l}\text { Not } \\
\text { report }\end{array}$ & 941 & RIFLE & $382 / 559$ & 40.6 & 11.0 & $\begin{array}{l}\text { advanced age, } \\
\text { cardiopulmonary } \\
\text { bypass time, } \\
\text { high body mass } \\
\text { index, } \\
\text { preoperative } \\
\text { renal } \\
\text { malperfusion, } \\
\text { perioperative } \\
\text { packed red } \\
\text { blood cells } \\
\text { transfusion, } \\
\text { preoperative } \\
\text { other organ } \\
\text { malperfusion }\end{array}$ & $3,0,3$ \\
\hline $\begin{array}{l}\text { Li, } 2020 \\
{[18]}\end{array}$ & China & $\begin{array}{l}\text { single center } \\
\text { retrospective } \\
\text { study }\end{array}$ & $\begin{array}{l}\text { type A } \\
\text { aortic } \\
\text { dissection }\end{array}$ & 47.6 & 335 & KDIGO & $241 / 94$ & 71.94 & 12.2 & $\begin{array}{l}\text { cardiopulmonary } \\
\text { bypass time, } \\
\text { high body mass } \\
\text { index, } \\
\text { perioperative } \\
\text { packed red } \\
\text { blood cells } \\
\text { transfusion, } \\
\text { preoperative } \\
\text { chronic kidney }\end{array}$ & $3,1,3$ \\
\hline
\end{tabular}




\begin{tabular}{|c|c|c|c|c|c|c|c|c|c|c|c|}
\hline & & & & & & & & & & $\begin{array}{l}\text { disease, } \\
\text { preoperative } \\
\text { chronic liver } \\
\text { disease, } \\
\text { postoperative } \\
\text { hypoproteinemia }\end{array}$ & \\
\hline $\begin{array}{l}\text { Liu Y, } \\
2020 \text { [17] }\end{array}$ & China & $\begin{array}{l}\text { single center } \\
\text { retrospective } \\
\text { cohort } \\
\text { study }\end{array}$ & $\begin{array}{l}\text { type A } \\
\text { aortic } \\
\text { dissection }\end{array}$ & 54.7 & 130 & KDIGO & $81 / 48$ & 63.08 & $\begin{array}{l}\text { Not } \\
\text { Report }\end{array}$ & $\begin{array}{l}\text { perioperative } \\
\text { packed red } \\
\text { blood cells } \\
\text { transfusion }\end{array}$ & $3,1,3$ \\
\hline $\begin{array}{l}\text { Wang, } \\
2020^{[15]}\end{array}$ & China & $\begin{array}{l}\text { single center } \\
\text { retrospective } \\
\text { cohort } \\
\text { study }\end{array}$ & $\begin{array}{l}\text { type A } \\
\text { aortic } \\
\text { dissection }\end{array}$ & 52.0 & 712 & KDIGO & $359 / 353$ & 50.4 & 15.9 & $\begin{array}{l}\text { preoperative } \\
\text { Cystatin C } \\
\text { concentration }\end{array}$ & $3,1,3$ \\
\hline $\begin{array}{l}\text { Liu T, } \\
2021^{[16]}\end{array}$ & China & $\begin{array}{l}\text { single center } \\
\text { retrospective } \\
\text { cohort } \\
\text { study }\end{array}$ & $\begin{array}{l}\text { DeBakey } \\
\text { type I } \\
\text { aortic } \\
\text { dissection }\end{array}$ & 48.7 & 115 & KDIGO & $61 / 54$ & 53.0 & $\begin{array}{l}\text { Not } \\
\text { Report }\end{array}$ & $\begin{array}{l}\text { high body mass } \\
\text { index }\end{array}$ & $3,1,3$ \\
\hline
\end{tabular}

Study

odds $\quad \%$

ID

ratio $(95 \% \mathrm{Cl}) \quad$ Weight

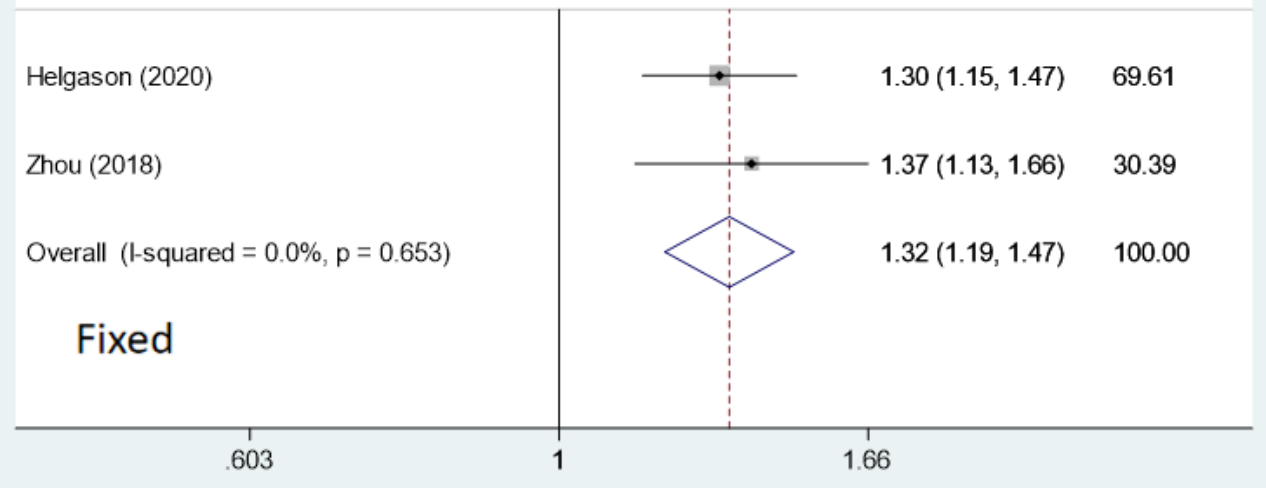

\section{Figure 2}

The forest plot of the advanced age after sensitivity analysis 


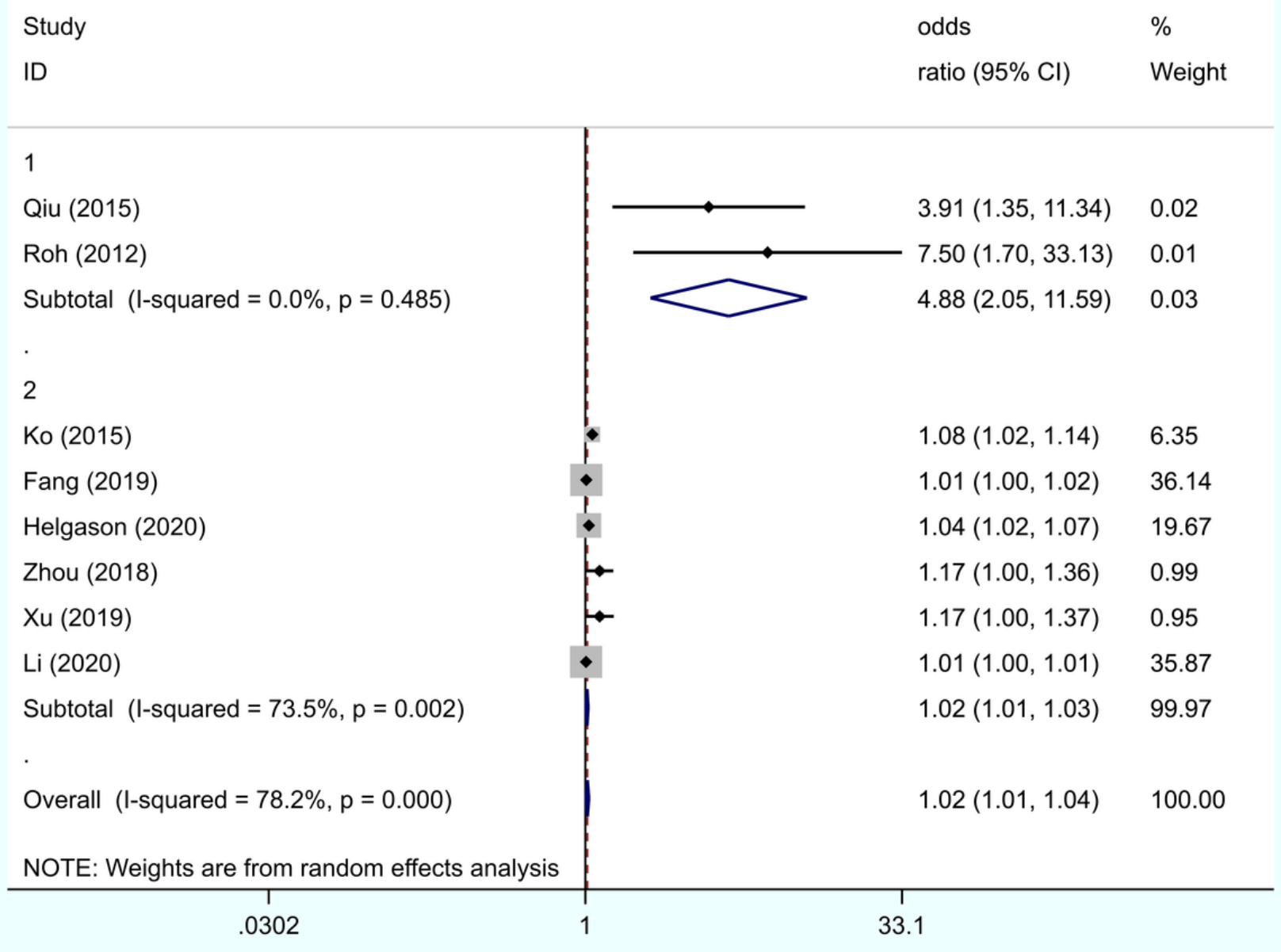

Figure 3

The subgroup analysis of long CPB time 


\begin{tabular}{|c|c|c|c|}
\hline Study & & odds & $\%$ \\
\hline ID & & ratio $(95 \% \mathrm{Cl})$ & Weight \\
\hline Helgason (2020) & $\rightarrow$ & $1.08(1.06,1.10)$ & 59.12 \\
\hline Li (2020) & & $1.19(1.05,1.33)$ & 30.65 \\
\hline Liu Y (2020) & & $1.31(1.01,1.70)$ & 10.24 \\
\hline Overall $(\mathrm{I}$-squared $=54.5 \%, p=0.111)$ & & $1.13(1.03,1.24)$ & 100.00 \\
\hline NOTE: Weights are from random effects analysis & & & \\
\hline $\begin{array}{c}1 \\
.587\end{array}$ & & & \\
\hline
\end{tabular}

\section{Figure 4}

The forest plot of RBC volume transfused perioperatively
Study
odds $\%$
ID
ratio $(95 \% \mathrm{Cl})$ Weight

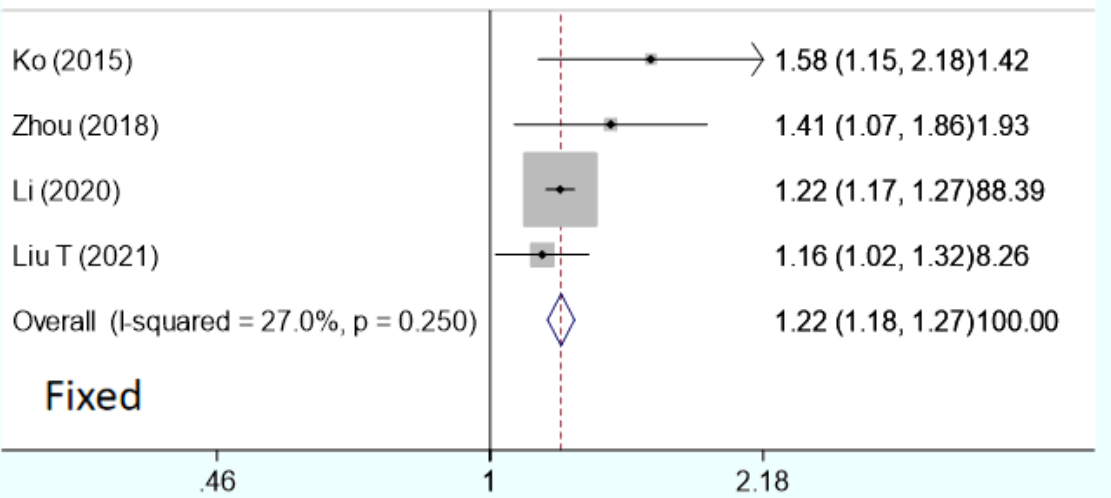

Figure 5

The forest plot of high BMI after sensitivity analysis 


\begin{tabular}{|c|c|c|}
\hline Study & odds & $\%$ \\
\hline ID & ratio $(95 \% \mathrm{Cl})$ & Weight \\
\hline Ko (2015) & $-9.06(2.82,29.12)$ & 26.52 \\
\hline Helgason (2020) & $4.39(2.18,8.85)$ & 73.48 \\
\hline Overall $(1-$ squared $=8.0 \%, p=0.297)$ & $5.32(2.92,9.71)$ & 100.00 \\
\hline Fixed & & \\
\hline .0343 & 29.1 & \\
\hline
\end{tabular}

Figure 6

The forest plot of preoperative renal malperfusion

\section{Supplementary Files}

This is a list of supplementary files associated with this preprint. Click to download.

- Supplementarymaterials.docx 